\title{
KARAKTERISASI STOMATA DAUN PEGAGAN (Centella asiatica (L.) Urban.) PADA KETINGGIAN WILAYAH BERBEDA DI PULAU AMBON
}

\author{
Hermalina Sinay ${ }^{1}$, Max H. Lesilolo ${ }^{2}$ \\ ${ }^{1}$ Program Studi Pendidikan Biologi, FKIP Universitas Pattimura \\ ${ }^{2}$ SMA Negeri 12 Ambon \\ Email: herlinbio@yahoo.co.id
}

\begin{abstract}
The purpose of this study was to determine the anatomical structure of pegagan leaves through stomata characterization at several different locations on Ambon Island. Survey method was used in this research. The sample was taken in nine villages were spread from lowlands to the highlands on Ambon Island. The procedure of semi-permanent preparations was done by whole mount method. Stomata characterization was done towards the stomata number, stomata density, and stomata index. The collected data were analyzed by descriptive analysis and performed in the form of table or figure. the research result shows that leaf with high stomata number was tend to high in stomata density and stomata index. Based on this research result, it could be conclude that there are no difference of stomatal structure of Pegagan leaves in all location were sample collected. The difference has shown by numbers, density, and stomatal index. The highest Numbers, density and stomatal index shown on Pegagan leaves in lowland, and the lowest that shown in this research on Pegagan leaves in highland.
\end{abstract}

Keywords: stomatal, structure, leaf, pegagan

\section{Pendahuluan}

Pegagan (Centella asiatica (L.) Urban.) merupakan tumbuhan liar yang termasuk famili Umbelliferae/Apiaceae. Di Asia, tumbuhan ini dikenal dengan nama Asiatic Pennywort, Indian pennyworth dan gotu cola (Padua \& Bunyapraphatsara, 1999). Secara umum, di Indonesia, tumbuhan ini disebut pegagan, tetapi di beberapa daerah di Indonesia dikenal dengan nama rumput kaki kuda atau antanan (Stennis, 1992). Sebagai tumbuhan liar, pegagan banyak ditemukan di kebun-kebun, ladang, tepi jalan, pematang sawah, dan di pekarangan. Tumbuhan ini berasal dari Asia tropik, dan bersifat kosmopolit, sehingga memiliki kisaran agroekologi yang luas dan mampu tumbuh dengan baik di daerah dataran rendah sampai dataran tinggi dengan ketinggian 2500 mdpl baik di tanah lembab, maupun tanah berpasir, ternaungi, maupun di tempat terbuka yang terkena cahaya penuh (Dalimartha, 2000; Sudarsono et al. 2002).

Dengan lingkungan tumbuh yang bervariasi, memungkinkan variasi sifat-sifat fenotipik pegagan, termasuk juga sifat anatomisnya sebagai akibat interaksi dengan faktor lingkungan. Hal ini disebabkan karena tumbuhan meskipun masih sejenis, jika tumbuh pada lingkungan yang sama, dapat berbeda-beda fenotipnya, apalagi pada lingkungan berbeda.

Penampilan yang berbeda pada tanaman yang sejenis yang tumbuh di lingkungan berbeda, disebabkan karena tumbuhan harus menyesuaikan diri dengan lingkungannya. Penyesuaian tumbuhan terhadap lingkungan dapat diamati pada berbagai level, baik morfologi, anatomi, fisiologi, bahkan molekulernya (Menzah, 2012). Li et al (2015) menyatakan bahwa mekanisme adaptasi tumbuhan tinggi (higher plants) terhadap lingkungan dapat diamati pada tingkat sel, jaringan dan organ tumbuhan. Menurut Sundari \& Atmaja (2011) ciri-ciri anatomi tanaman yang penting diamati untuk mengetahui hubungan antara tanaman dengan lingkungan adalah stomata pada daun.

Di Pulau Ambon, pegagan tumbuh menyebar pada semua wilayah dari dataran rendah sampai dataran tinggi. Dengan pertumbuhan pada lokasi yang berbeda ini, memungkinkan adanya perbedaan karakter anatomi, khususnya stomata. Xu \& Zhou (2008) menyatakan bahwa stomata merupakan lubang pada permukaan daun yang berfungsi dalam pertukaran gas antara daun dengan lingkungan, sedangkan Hidayat (1995) menyatakan bahwa stomata merupakan celah yang dibatasi oleh dua sel epidermis khusus yaitu sel penutup dan sel tetangga. Menurut Song-Ai \& Banyo (2012), stomata merupakan objek yang sering diteliti dan diidentifikasi dalam kaitan dengan upaya memahami respon tanaman terhadap kondisi lingkungan tumbuh yang bervariasi. Demikian halnya dengan pegagan di Pulau Ambon. Diduga bahwa lingkungan tumbuh yang bervariasi dari dataran rendah sampai dataran tinggi, kemungkinan mempengaruhi karakteristik stomata pada daun pegagan tersebut. Dengan demikian, 
maka tujuan penelitian ini adalah untuk mengetahui struktur anatomi daun pegagan melalui karakterisasi stomata pada beberapa lokasi yang berbeda di Pulau Ambon.

\section{2. $\quad$ Metode}

Pendekatan yang digunakan dalam penelitian ini yaitu pendekatan survei yaitu sampel diambil pada sembarang tempat di sembilan lokasi ditemukannya tanaman pegagan di Pulau Ambon. Lokasi penelitian adalah beberapa desa di wilayah Pulau Ambon yaitu Desa Laha, Desa Hative Besar, Desa Wayame, Desa Poka, Desa Suli, Desa Passo, Desa Lateri, Negeri Kilang, dan Desa Kusu-Kusu Sereh. Desa-desa ini tersebar dari dataran rendah sampai dataran tinggi di Pulau Ambon. Pada satu lokasi diambil 2 tanaman pada jarak yang tidak berdekatan dan dianggap sebagai ulangan. Dari satu tanaman yang diambil pada satu lokasi, diambil 3 helaian daun. Dari satu helaian daun tersebut dibuat satu potongan daun berukuran $1 \times 1 \mathrm{~cm}^{2}$. Potongan daun tersebut kemudian direndam dalam alkohol $70 \%$ dan dibawa ke Laboratorium untuk dibuatkan preparat semi permanen.

Prosedur pembuatan preparat semi permanen untuk karakterisasi stomata dengan metode whole mount (Ruzin, 1999, Sinay et al., 2015). Potongan daun yang sudah dimasukkan dalam alkohol $70 \%$ kemudian difiksasi menggunakan FAA (formalin, alkohol $70 \%$, asam asetat dengan perbandingan $5: 90: 5$ ) selama 36 jam. Fiksatif kemudian dibuang, dan diganti dengan larutan pemutih komersil (klorox) $10 \%$ sampai daun bening transparan. Setelah itu, dilakukan pewarnaan dengan safranin $1 \%$ dalam alkohol $70 \%$ selama 1 menit, dilanjutkan dengan pencucian dalam alkohol bertingkat (70, 80, 90, dan $100 \%)$ masing-masing 3 menit. Potongan daun kemudian direkatkan di atas kaca objek yang telah ditetesi gliserin, ditutup dengan kaca penutup, dan diamati di bawah mikroskop, dan difoto menggunakan kamera Optilab yang terkoneksi dengan komputer. Karakterisasi stomata yang dilakukan meliputi: jumlah stomata, kerapatan stomata, dan indeks stomata. Perhitungan kerapatan stomata dilakukan pada permukaan bawah daun (sisi abaksial) pada lima bidang pandang dengan pembesaran 400x, menggunakan rumus dari Lestari (2006), Haryanti (2010), dan Sundari \& Atmaja (2011). Kemudian dilakukan perhitungan kerapatan stomata total yang diperoleh dari rata-rata perhitungan pada tiga titik pengamatan dengan rumus dari Lestari (2006). Setelah itu dilakukan perhitungan Indeks stomata (IS) menggunakan rumus dari Wallis (1965). Data hasil perhitungan kerapatan dan indeks stomata dianalisis secara deskriptif dan disajikan dalam bentuk Tabel dan gambar.

\section{Hasil Penelitian}

Pegagan merupakan tumbuhan kosmopolit yang penyebarannya sangat luas, tumbuh liar pada sembarang tempat, dan umumnya ditemukan di pesawahan, ladang, pekarangan, dan juga sebagai gulma pada lahan pertanian. Pegagan dapat ditemukan pada semua jenis tanah yakni berpasir, lempung, alluvial, regosol, podzolik, sampai tanah humus yang subur. Pegagan juga tumbuh dengan baik di daerah dataran rendah sampai dataran tinggi dan pegunungan.

Lokasi pengambilan sampel tumbuhan pegagan dalam penelitian ini adalah pada sembilan desa di Pulau Ambon. Secara geografis wilayah pulau Ambon berada pada posisi astronomis $03^{\circ}-04^{\circ}$ Lintang Selatan dan $128^{\circ}-$ $129^{\circ}$ Bujur Timur (Bandjar, 2014). Kesembilan lokasi tersebut tersebar dalam beberapa wilayah Kecamatan dan termasuk dalam wilayah administratif kota Ambon dan Kabupaten Maluku Tengah (Tabel 1).

Tabel 1. Lokasi Pengambilan Sampel Tumbuhan Pegagan

\begin{tabular}{|c|c|c|c|c|c|}
\hline No. & Nama Lokasi & Kecamatan & Kabupaten/Kota & $\begin{array}{l}\text { Ketinggian dari } \\
\text { permukaan laut } \\
(\mathrm{mdpl})\end{array}$ & $\begin{array}{l}\text { Suhu udara saat } \\
\text { pengambilan } \\
\text { sampel }\end{array}$ \\
\hline 1. & Desa Laha & Teluk Ambon Baguala & Ambon & $10-20$ & $30^{\circ} \mathrm{C}$ \\
\hline 2. & Hative Besar & Teluk Ambon Baguala & Ambon & $10-20$ & $30^{\circ} \mathrm{C}$ \\
\hline 3. & Wayame & Teluk Ambon Baguala & Ambon & $10-20$ & $30^{\circ} \mathrm{C}$ \\
\hline 4. & Poka & Teluk Ambon Baguala & Ambon & $10-20$ & $30^{\circ} \mathrm{C}$ \\
\hline 5. & Passo & Teluk Ambon Baguala & Ambon & $10-10$ & $30^{\circ} \mathrm{C}$ \\
\hline 6. & Lateri & Teluk Ambon Baguala & Ambon & $10-20$ & $30^{\circ} \mathrm{C}$ \\
\hline 7. & Suli & Salahutu & Maluku Tengah & $10-20$ & $30^{\circ} \mathrm{C}$ \\
\hline 8. & Kilang & Sirimau & Ambon & $450-750$ & $29^{\circ} \mathrm{C}$ \\
\hline 9. & $\begin{array}{l}\text { Kusu-Kusu } \\
\text { Sereh }\end{array}$ & Sirimau & Ambon & $450-700$ & $29^{\circ} \mathrm{C}$ \\
\hline
\end{tabular}


Struktur anatomi daun yang diamati dalam penelitian ini adalah stomata yang meliputi jumlah, kerapatan, dan indeks stomata. Stomata yang diamati adalah pada permukaan bawah (sisi abaksial) daun pegagan (C. asiatica (L.) Urban.). Xu \& Zhou (2008) menyatakan bahwa stomata merupakan lubang pada permukaan daun yang berfungsi dalam pertukaran gas antara daun dengan lingkungan, sedangkan Hidayat (1995) menyatakan bahwa stomata merupakan celah yang dibatasi oleh dua sel epidermis khusus yaitu sel penutup dan sel tetangga.

Hasil penelitian ini menunjukkan bahwa tidak terdapat perbedaan struktur stomata baik pada daerah dataran rendah maupun dataran tinggi. Berdasarkan hasil pengamatan, maka dapat dilihat bahwa stomata pada daun pegagan yang dikoleksi dari 9 lokasi berbeda di Pulau Ambon memiliki struktur yang sama yaitu terdiri dari sel penutup dan sel tetangga. Sel penutup letaknya sejajar dengan lubang (celah) stomata. Hanif et al., (2016) menyatakan bahwa sel penutup pada $C$. asiatica L. Urban berbentuk ginjal dengan tipe stomata anisositik. Di bagian luar sel penutup terdapat sel tetangga yang bentuknya berbeda dengan sel-sel penutup. Diduga sel-sel tetangga ini adalah sel-sel epidermis yang mengalami modifikasi menjadi sel tetangga. Hanif et al., (2016) menyatakan bahwa pada daun $C$. asiatica L. Urban di sekitar sel penutup terdapat sel-sel epidermis yang disebut sel-sel subsidair atau sel aksesoris. Bentuk sel tetangga ini berbeda dengan bentuk sel penutup maupun sel epidermis di sekitarnya. Jumlah sel tetangga bervariasi. Umumnya dapat diamati terdapat satu, dua, atau tiga sel tetangga dengan bentuk yang tidak beraturan, ada yang besar dan ada yang kecil. Ada yang letaknya sejajar dengan sel penutup, dan ada yang letaknya berlawanan arah dengan sel penutup (Gambar 1 dan Gambar 2).

Epidermis pada daun $C$. asiatica (L.) Urban. memiliki dinding yang tipis dengan bentuk dan ukuran bervariasi. Sel-sel epidermis ada yang berukuran besar dan ada yang kecil, memanjang, memendek, atau membulat bersegilima atau bersegi enam tidak beraturan, serta tersusun rapat tetapi tidak searah atau tidak beraturan, tanpa adanya ruang antar sel (Gambar 1 dan Gambar 2).
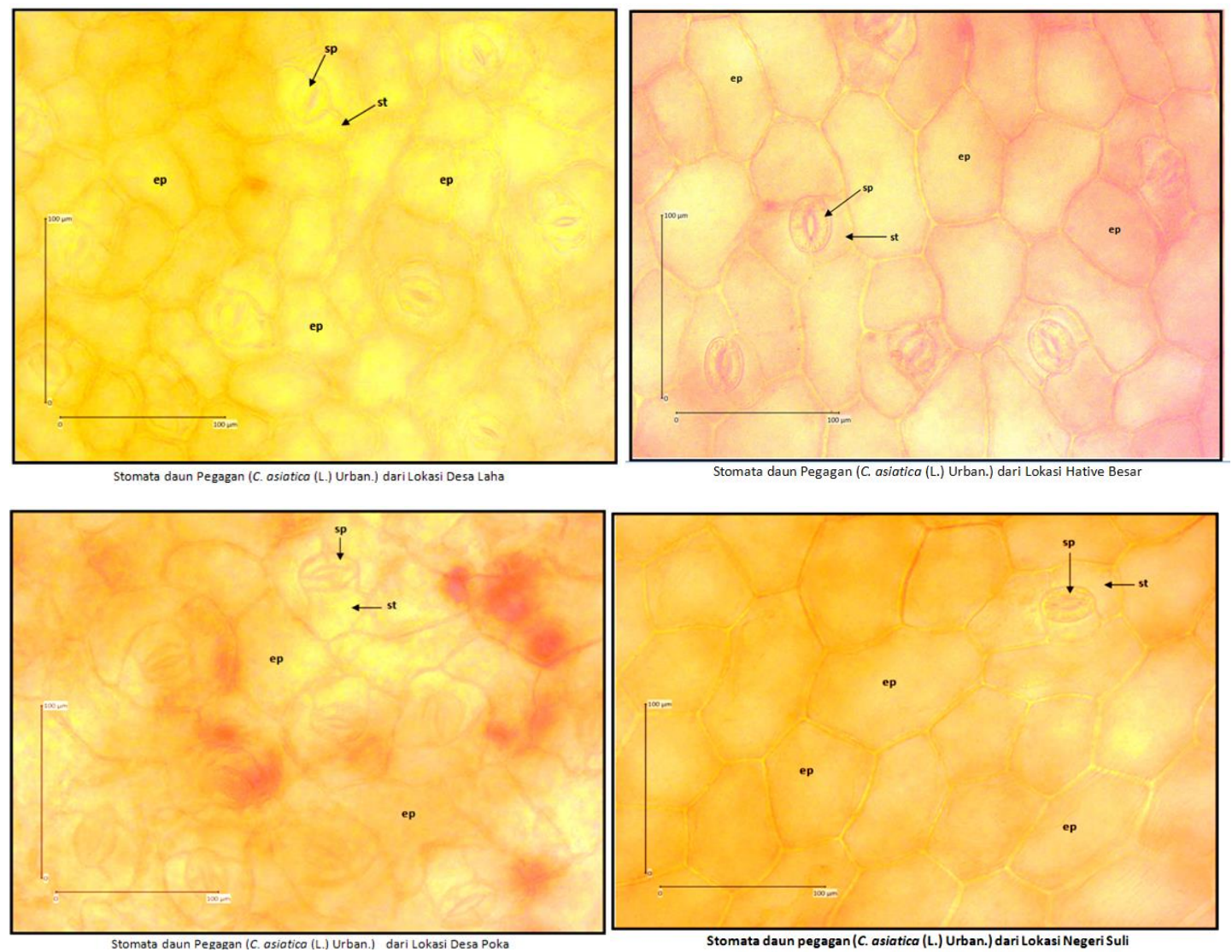

Gambar 1. Stomata daun pegagan (C. asiatica (L.) Urban.). Ket: sp: sel penutup, st: sel tetangga, ep: epidermis 


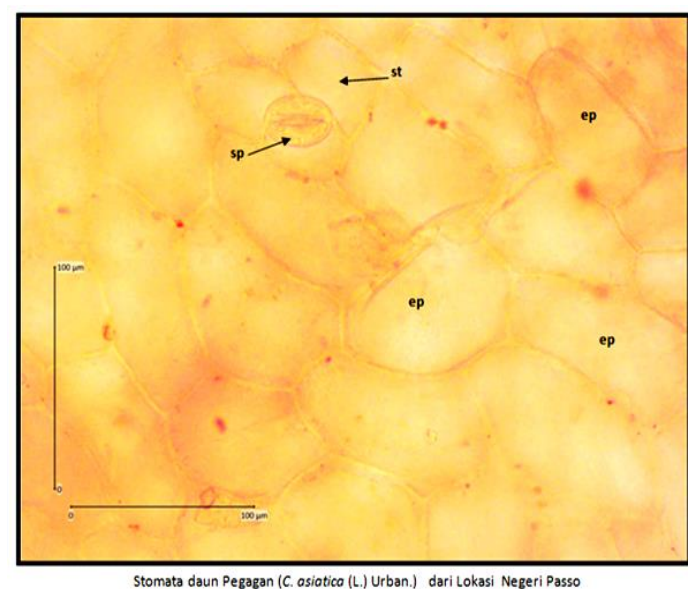

Stomata daun Pegagan (C. asiatico (L.) Urban.) dari Lokasi Negeri Passo

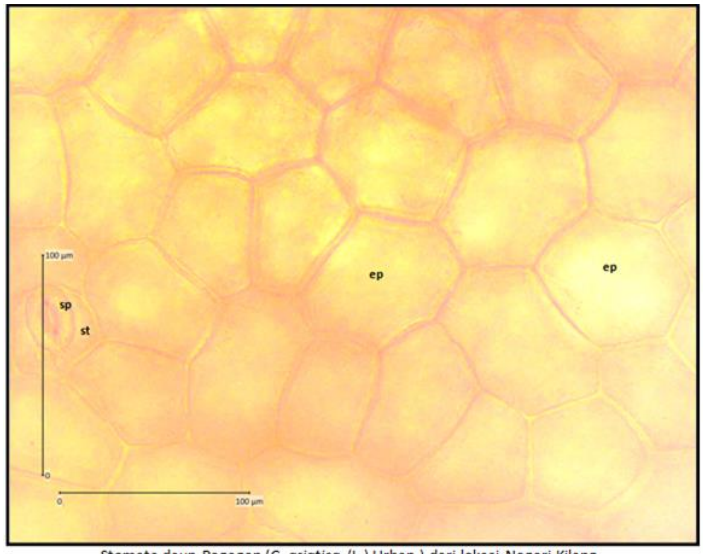

Stomata daun Pegagan (C. asiatica (L.) Urban.) dari lokasi Negeri Kilan
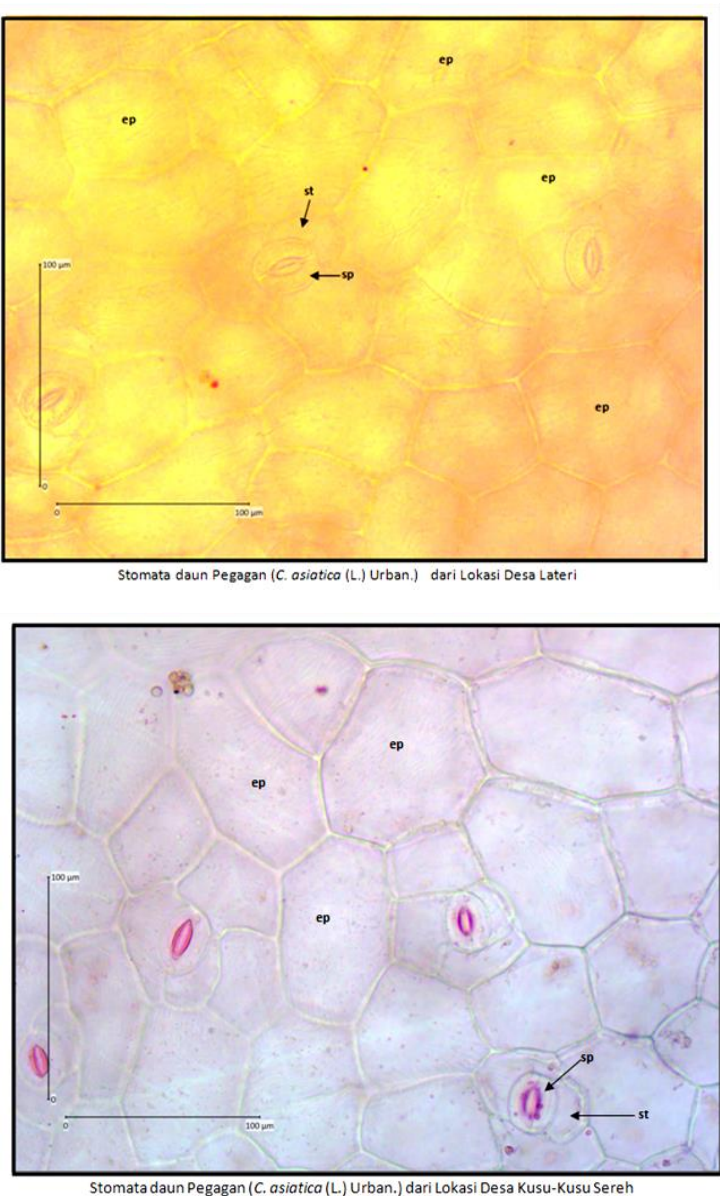

Gambar 2. Stomata daun pegagan (C. asiatica (L.) Urban.). Ket: sp: sel penutup, st: sel tetangga, ep: epidermis

Letak stomata menyebar secara tidak teratur. Ini sesuai dengan yang dikemukakan oleh Cason \& Gray (2008) bahwa tidak seperti tumbuhan monokotil yang stomatanya cenderung sejajar, pada dikotil stomata relatif tersusun secara acak dan tidak beraturan. Antara satu stomata dengan stomata yang lain umumnya dibatasi oleh satu sampai dua sel epidermis. Cason \& Gray (2008) menyatakan bahwa letak stomata yang tidak berdekatan ini bertujuan memaksimalkan fungsi stomata dalam pertukaran gas, sehingga tidak terjadi tumpang tindih dalam pertukaran gas.

Berbeda dengan hasil pengamatan struktur stomata, hasil perhitungan karakter stomata yang meliputi jumlah stomata, indeks dan kerapatan stomata menunjukan adanya variasi pada setiap lokasi. Hasil perhitungan jumlah, indeks, dan kerapatan stomata daun Pegagan (C. asiatica (L.) Urban.) ditunjukan pada Gambar 3. 


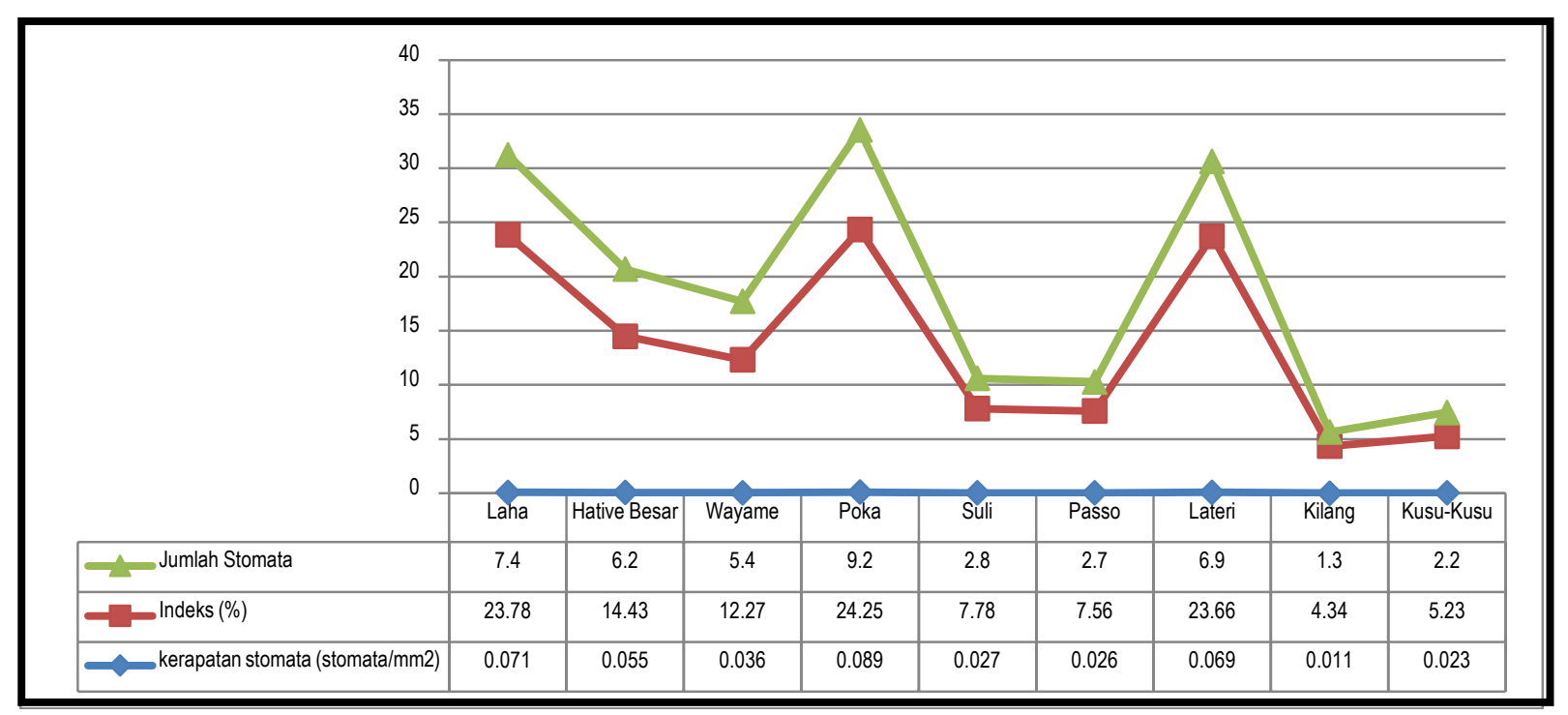

Gambar 3. Jumlah, kerapatan dan indeks stomata daun Pegagan (C. asiatica (L.) Urban.) pada beberapa lokasi di Pulau Ambon

Berdasarkan data pada Gambar 3 dapat dilihat bahwa jumlah, kerapatan dan indeks stomata tertinggi adalah pada daerah dataran rendah, dan terendah pada daerah dataran tinggi. Gambar 3 juga menunjukkan bahwa daun dengan jumlah stomata tinggi, cenderung memiliki kerapatan stomata dan indeks stomata tinggi. Hal ini menunjukkan bahwa jumlah stomata berbanding lurus dengan indeks dan kerapatan stomata. Dengan kata lain, semakin banyak jumlah stomata, maka semakin rapat stomata tersebut, dan semakin tinggi indeks stomata. Hal ini sesuai dengan pendapat Haworth et al. (2010) yang menyatakan bahwa jumlah/frekuensi stomata berkaitan dengan dan dapat diukur melalui indeks stomata dan kerapatan stomata. Ini berarti bahwa dengan mengetahui indeks dan kepadatan stomata dapat diketahui atau dapat diprediksi jumlah atau frekuensi stomata, karena kepadatan stomata merupakan jumlah stomata per satuan luas permukaan daun, sedangkan indeks stomata merupakan perbandingan antara stomata dan epidermis. Daun tumbuhan dengan jumlah stomata tinggi dapat memiliki jumlah epidermis sedikit dengan ukuran besar atau sebaliknya, jumlah epidermis banyak tetapi berukuran kecil.

Jika dikaji berdasarkan ketinggian wilayah lokasi pengambilan sampel, maka stomata dengan jumlah tertinggi adalah lokasi yang termasuk wilayah dataran rendah dengan ketinggian rata-rata kurang dari 100 mdpl, sedangkan pada lokasi desa Kilang dan Kusu-Kusu yang berada pada dataran tinggi, memiliki jumlah stomata yang paling rendah.

Tingginya jumlah stomata pada daun tumbuhan pegagan pada daerah dataran rendah diduga dipengaruhi oleh kondisi lingkungan tempat tumbuh. Kondisi lingkungan tempat tumbuh yang dimaksud adalah ketersediaan cahaya matahari. Perlu dijelaskan bahwa lokasi pengambilan sampel di wilayah dataran rendah adalah di pinggiran jalan umum yang merupakan wilayah terbuka atau terpapar cahaya matahari penuh. Dengan semakin kuat intensitas cahaya matahari, maka akan mempengaruhi pembentukan stomata selama perkembangan daun. Hasil ini sejalan dengan hasil penelitan yang dilaporkan oleh beberapa peneliti yang menemukan bahwa jumlah, kepadatan, dan indeks stomata akan meningkat pada perlakuan cahaya tinggi yaitu pada daun tumbuhan misalnya pada Rotala hippuris (Momokawa et al, 2011), dan pada daun kecambah rape (Xu-Yang et al. 2017).

Tinggi rendahnya frekuensi, indeks dan kepadatan stomata juga dipengaruhi oleh faktor lain selain intensitas cahaya yaitu konsentrasi $\mathrm{CO}_{2}$ dan temperatur. Beberapa hasil penelitian menemukan bahwa pada daerah dengan konsentrasi $\mathrm{CO}_{2}$ tinggi dan suhu tinggi, karakteristik stomata mengalami reduksi yaitu jumlah, indeks dan kepadatan mengalami penurunan (Poole et al. 2000; Lawson et al. 2000; Haworth et al. 2010). Pernyataan ini tentu saja berbeda dengan hasil penelitian ini yaitu bahwa pada daerah dataran rendah, justru memiliki karakteristik stomata yang lebih tinggi. Perbedaan hasil ini dapat saja terjadi, diduga disebabkan karena spesies tumbuhan itu sendiri. Taub (2010) menyatakan bahwa ada spesies yang karakter stomatanya dapat menurun, meningkat dan tetap normal pada peningkatan konsentrasi $\mathrm{CO}_{2}$. Kemungkinan, pegagan termasuk tumbuhan yang karakter stomatanya justru mengalami peningkatan jika berada pada kondisi lingkungan dengan konsentrasi $\mathrm{CO}_{2}$ tinggi. Hasil penelitian ini menemukan bahwa di dataran rendah, jumlah, indeks, dan kepadatan stomata daun pegagan 
justru tinggi. Ini menunjukkan bahwa tumbuhan pegagan sebenarnya memberikan manfaat yang baik terhadap lingkungan karena dengan jumlah stomata yang tinggi pada kondisi lingkungan $\mathrm{CO}_{2}$ tinggi, dapat membantu menyerap $\mathrm{CO}_{2}$ dari lingkungan. Sedangkan dalam kaitan dengan temperatur, jumlah, indeks, dan kepadatan stomata akan rendah jika berada pada lingkungan dengan suhu tinggi. Namun dalam penelitian ini, daun pegagan di dataran rendah dengan suhu cenderung tinggi justru memiliki jumlah, indeks, dan kepadatan stomata tinggi. Ini berarti bahwa pegagan memiliki kemampuan mengatur sirkulasi air dalam tubuhnya berkaitan dengan laju transpirasi. Jika suhu tinggi dan stomata banyak, maka transpirasi juga akan meningkat, tetapi peningkatan ini harus disesuaikan dengan laju penyerapan air oleh akar tanaman. Kemungkinan, tumbuhan pegagan memiliki kemampuan mengatur kestabilan air dalam tubuhnya sehinga dapat mengatur laju transpirasi dengan jumlah stomatanya yang banyak, tetapi dapat tetap tumbuh pada suhu tinggi. Ini kemungkinan juga dipengaruhi oleh adanya lapisan kutikula yang terdapat pada permukaan daun pegagan sehingga membantu mencegah penguapan air yang berlebihan, meskipun berada pada suhu tinggi.

\section{Kesimpulan}

Berdasarkan hasil penelitian dan pembahasan, maka disimpulkan bahwa tidak ada perbedaan struktur stomata daun pegagan pada semua lokasi. Perbdaan hanya ditunjukkan pada jumlah, kepadatan, dan indeks stomata. Jumlah, kepadatan dan indeks stomata tertinggi dimiliki oleh daun pegagan di daerah dataran rendah, dan terendah dimiliki oleh stomata di daerah dataran tinggi.

\section{Daftar Pustaka}

Cason, S., \& Gray, J. E. (2008). Influence of environmental factors on stomatal development. New Phytologist, (178), 9-23

de Padua, L.S., Bunyapraphatsara, N., \& Lemmens, R.H.M.J. (1999). Plant Resources of South East Asia. Backhuys Publishers, Leiden, 12(1).

Dalimartha, S. 2000. Atlas Tumbuhan Obat Indonesia 2. Jakarta: Trubus Agriwidya. 214 hal.

Haworth, M., Heath, J., \& McElwain, J.C. (2010). Differences in the response sensitivity of stomatal index to atmospheric $\mathrm{CO}_{2}$ among four genera of Cupressaceae conifers. Annals Botany, 105(3), 411-418. Published online 2010 Jan 20. doi: 10.1093/aob/mcp309

Haryanti, S. (2010). Jumlah dan distribusi stomata pada daun beberapa spesies tanaman dikotil dan monokotil. Buletin Agronomi dan Fisiologi, XVIII (2), 21-28

Hanif, U., Mukhtar, A., Ud Din Khan, Z., Hussain, T., Jabeen, R., \& Butt, G. Y. (2016). Anatomical study of two Hydrophytes - Pistia stratiotes L. and Centella asiatica (L.) Urban. BIOLOGIA (PAKISTAN), $62(1), 151-155$

Lestari, E.G. 2006. Hubungan antara kerapatan stomata dengan ketahanan kekeringan pada somaklon Padi Gajahmungkur, Towuti dan IR64. Biodiversitas 7 (1): 44-48

Lenny L.R. Kouwenberg Jennifer C. McElwain. (2007). The effect of light intensity and temperature changes on the stomatal and epidermal morphology of Quercus kelloggi: implications for paleoelevation reconstruction. Department of Geology Field Museum of Natural History 1400 South Lake Shore Drive Chicago, 60605, IL, USA lkouwenberg@fmnh.org

Li, X., Li, Y., Zhang, Z., \& Li, X. (2015). Influences of Environmental Factors on Leaf Morphology of Chinese Jujubes. PLoS ONE, 10(5), e0127825. http://doi.org/10.1371/journal.pone.0127825.

Menzah, D.B. (2012). Leaf anatomical variation in relation to stress Tolerance among some woody species on the accra plains of Ghana. Journal of Plant Development,19, 13-22.

Momokawa, N., Kadono, Y., \& Kudoh, H. (2011). Effects of light quality on leaf morphogenesis of a heterophyllous amphibious plant, Rotala hippuris. Annals Botany, 108(7), 1299-1306. Published online 2011 Sep 6. doi: 10.1093/aob/mcr236

Poole, I., Lawson, T., Weyers, J.D.B., Raven, J.A. (2000). Effect of elevated $\mathrm{CO}_{2}$ on the stomatal distribution and leaf physiology of Ilnus glutinosa. New Pytologist, 145, 511-521.

Ruzin, S.E. Plant Microtechnique and Microscopy. New York Oxford : Oxford University Press

Sinay, H., Arumingtyas, E.E., Harijati, N., \& Indriyani, S. (2015). Stomata characterization of local corn cultivars which is grown under field condition in Kisar Island Southwest Maluku Regency. Proceeding The 5th Annual Basic Science International Conference, 5(1), 96-99. 
Sundari, T., \& Atmaja, R. P. (2011). Bentuk sel epidermis, tipe dan indeks stomata 5 genotipe kedelai pada tingkat naungan berbeda. Journal Biologi Indonesia, 7(1), 67-79.Buletin Agronomi dan Fisiologi, XVIII (2), 21-28

Taub, D. (2010) Effects of rising atmospheric concentrations of carbon dioxide on plants. Nature Education Knowledge, 3(10), 21

Van Steenis,C.G.G.J. 1992. Flora. Penerjemah : M.Soeryowinoto, dkk. Cetakan 5. PT.Pradnya Paramita.Jakarta. Wallis, T.E. 1965. Analytical Mycroscopy. Boston Little Brown and Company

Xu-Yang, Y., Xiao-Ying, L., Zhi-Gang, X., \& Xue-Lei. J. (2017). Effect of light intensity on leaf microstructure and growth of rape seedlings cultivated under a combination of red and blue LEDs. Journal of Integrative Agriculture, 16(1), 97-105.

Xu, Z., \& G. Zhou. (2008). Responses of leaf stomatal density to water status and its relationship with photosynthesis in a grass. Journal of Experimental Botany, 59, 12: 3317-3325 